\title{
Steroids in the assessment of prenatal development
}

\author{
Geoffrey Chamberlain \\ M.D., F.R.C.S., M.R.C.O.G.
}

\author{
YVONNE KITCHIN \\ Ph.D., M.Sc.
}

\author{
Institute of Obstetrics and Gynaecology, University of London
}

\begin{abstract}
Summary
Methods for identifying the fetus at risk and monitoring fetal well-being as pregnancy progresses are now an established part of prenatal care in the Western World.

In this short review the use of steroids in the assessment of prenatal development is discussed. The metabolism of oestrogens, progestogens, corticosteroids and androgens during pregnancy is outlined and the relative merits, in terms of usefulness and practicability, of urinary and plasma steroid assays are discussed.
\end{abstract}

AFTER conception, some embryonic cells develop into the placenta while others become the fetus. Despite the common origin, differences of function cause variations in the pattern of enzyme distribution leading to different biosynthetic capacities in each part of the feto-placental unit. However, in some instances, enzymes absent from one tissue are present in another, so that fetus and placenta together can synthetize steroids which separately they could not. Diczfalusy in Stockholm pioneered the idea of a single endocrine unit of the two tissues coming from a common origin-the feto-placental unit. In this short review, details cannot be given but the reader is referred to Diczfalusy (1969) and MacNaughton (1969) both of whom review in detail the background of this material.

Some of the steroid hormones partly metabolized in the placenta, are passed to the fetus for modification; others start in the fetal adrenal gland and act as precursors for hormones that can be synthetized by the placenta. Among such steroid hormones are oestrogens, progestogens, corticosteroids, and androgens, and assay of certain of these hormones in maternal blood and urine can give an indication of the well-being of the feto-placental unit. The metabolism of the various groups of steroid hormones and their usefulness in monitoring the feto-placental unit will be discussed. However, the most practical

Correspondence: Dr Yvonne Kitchin. Department of Endocrinology, Chelsea Hospital for Women, Dovehouse Street, London SW3. measures of pre-natal development in current use involve maternal oestrogen excretion.

\section{Feto-placental metabolism of steroid hormones Oestrogens}

Many oestrogens are derived from the parent nucleus oestrane but only three have assumed importance in human biology up to the present. Oestradiol-17 $\beta$ and oestrone are present in the highest concentrations in the non-pregnant female while oestriol is produced in pregnancy in large amounts. Oestriol together with its conjugates accounts for much of the increase in total ozstrogen found at this time. Both oestradiol and oestrone can be synthetized by the placenta but their excretion in pregnancy is very small compared with that of oestriol. Pregnenolone is converted in the fetal adrenal gland to dehydroepiandrosterone sulphate (DHAS), the fetal tissues being rich in sulphate transferases. DHAS is then hydroxylated in the fetal liver to $16 \alpha$-hydroxydehydroepiandrosterone sulphate (16 $\alpha-\mathrm{OH}$ DHAS). This can then pass back to the placenta where it is hydrolysed to the free steroid $16 \alpha-\mathrm{OH}$ DHA which is then aromatized to oestriol. Although the placenta alone cannot synthetize oestriol, it can aromatize androstenedione to oestrone which interconverts with oestradiol but these are not used for oestriol synthesis as the placenta does not possess the necessary hydroxylating enzymes (Levitz, Emerman and Dancis, 1962). In pregnancy, therefore, the developing fetus is responsible for the production of large quantities of neutral precursors which the placenta then aromatizes to oestriol; this constitutes the major portion of the total oestrogens excreted in the maternal urine.

\section{Progestogens}

In early pregnancy, progesterone is produced by the corpus luteum of the ovary while later it is mostly metabolized by the placenta (Diczfalusy and Troen, 1961). The route of biosynthesis is not fully understood but progesterone is probably synthetized from pregnenolone (Pion et al., 1965) and pregnenolone sulphate (Pion, Conrad and Wolf, 1966) in 
middle and late pregnancy. Progesterone circulates to the fetus where it is metabolized mainly by the liver and adrenal glands but only a small portion is transferred back to the placenta and this contributes very little to maternal excretion levels. Thus, most of the pregnanediol excreted by the mother is produced by the placenta and the fetal contribution is small.

In pregnancy, progesterone metabolism is usually assessed by measuring its urinary metabolite, pregnanediol. Levels rise steadily until the end of pregnancy, dropping sharply just before labour. Progesterone activity might alternatively be estimated in a biological assay when the effect on the morphology of vaginal epithelial cells can be assessed. In addition, plasma progesterone levels can now be measured directly by saturation analysis techniques.

\section{Corticosteroids}

Synthesis of corticosteroids, which are concerned with fetal homeostasis, can occur in both the fetus and the placenta. The fetal adrenal is relatively much larger than the adult gland and is functional in intrauterine life. After the stress of vaginal delivery, cortisol levels in fetal blood are much higher than those after a Caesarean section, particularly if that operation is done before labour. Levels are higher after spontaneous labour than if induction occurred, implying that cortisol may be involved with the onset of labour. Whilst the placenta can metabolize small amounts of cortisol and other corticosteroids, the major source of these is the fetal adrenal where many of the corticosteroids are formed from progesterone and then rapidly converted to sulphates. At present there is no practical way of measuring intrauterine fetal cortisol or cortisone production which may help the assessment of fetal well-being.

\section{Androgens}

The level of testosterone in the umbilical cord plasma of male fetuses is ten times as high as that in the plasma of females (Solomon, 1967). This hormone is probably produced from the placenta and the testis in varying proportions throughout pregnancy. Dehydroepiandrosterone (DHA) and DHAS can be produced from pregnenolone in the fetal adrenal and on reaching the placenta can be transformed into testosterone and androstenedione, some of which may remain after aromatization to oestrogens and return to the fetal circulation (Lamb et al., 1967).

In addition, the placenta can produce both steroids by hydrolysis and oxidation of DHAS secreted by the maternal adrenals, while in early pregnancy at least, the fetal testis may be able to convert 17-hydroxyprogesterone to androstenedione and testosterone (Solomon et al., 1967). Placental progesterone could therefore be the basic substance from which nearly all androgens are produced; the exact pathway may depend upon which enzyme is active which, in turn, is related to the period of gestation. In practice it is probably the fetal testis which is most commonly concerned with production of androgens, although the placenta in either sex could be equally involved. At present there is no practical measure of fetal androgens which can be used to assess the outcome of pregnancy.

Assessing pre-natal development from steroid assays

In the 1950 s, assay of urinary pregnanediol was considered an important measure of fetal wellbeing. Urinary excretion in maternal $24-\mathrm{hr}$ specimens was used to differentiate pregnancies where placental function was poor and those where the placenta was adequate (Russell et al., 1957). However, it was soon appreciated that these measures correlated more with placental size than with fetal outcome. In the early sixties, it was realized that the excretion of oestrogens, mostly oestriol, was a more sensitive index of fetal well-being and so it is this estimation which has become the most widely used biochemical measure of pre-natal development in the Western World at the moment.

Oestrogens are present in all body fluids; they are excreted in the urine and it is convenient to measure the oestrogen excretion for the whole day by the collection of 24-hr specimens. Whilst estimations measure total oestrogens, the results are ofter reported as being that of oestriol, the major constituent. Hydrolysis liberates the conjugated steroids and a Kober reaction is used; the Brown method (Brown, Bulbrook and Greenwood, 1957) has been improved with semi-automatic techniques so that one technician can deal with over forty samples a day giving results within $6 \mathrm{hr}$.

Twenty-four hour collections of urine have inherent disadvantages. They depend upon filtration through the kidney which may itself be the seat of disease and collection in containers which is often inconvenient resulting in human error, either of omission or commission. Drugs, such as mandelamine, can affect oestrogen excretion in the urine, while high or low fluid intakes could also alter the concentration. There are considerable day-to-day variations in the excretion of these steroids. Klopper and Diczfalusy (1969) pointed out that, given a daily coefficient of variation in excretion of about $30 \%$, values of at least $60 \%$ above or below the mean must occur before alterations become significant. Further, while single values may be useful if they are grossly reduced, only a series of readings can show a trend. Any method which requires serial observations to show significant alterations is of most use to indicate chronic abnormalities.

Serial urinary oestrogen excretion may be used in the management of intrauterine growth retardation, 


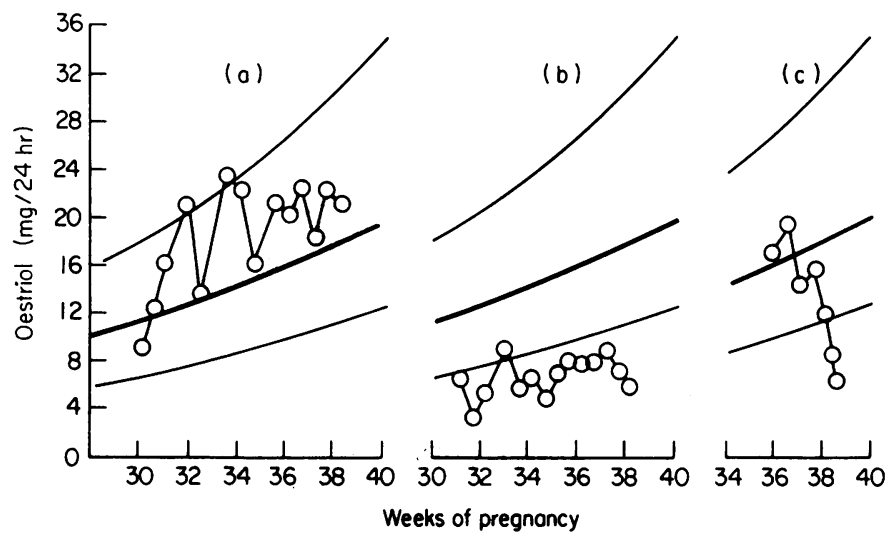

FIG. 1. Patterns of oestrogen excretion (mean \pm 2 s.d.) in the last weeks of pregnancy. (a) Normal; (b) chronic placental malperfusion; (c) acute placental malperfusion. (Taken from Chamberlain, 1975.)

pre-eclampsia or post-maturity. Figure 1 shows the pattern of oestrogen excretion in some such situations.

Fetal intrauterine growth retardation can occur with no obvious symptoms. Oestrogen excretion can be used as a guide for the optimum time of delivery, a falling series of readings indicating poor fetal adrenal function, but it does not give a good prospective indication of when fetal death might occur.

In pre-eclampsia, oestrogen excretion can be related to the severity of the condition and may reassure the obstetrician of continued fetal wellbeing; this staves off induction of labour allowing a more mature baby to be born. In essential hypertension, oestriol excretion is not so useful unless a supra-added pre-eclampsia develops.

Postmaturity is accompanied by an increased risk of fetal death, and several workers have shown that so long as oestriol excretion is normal the fetus is not at high risk. If the output drops, there is a higher incidence of problems in labour and fetal mortality. In postmaturity, the oestriol levels can fall suddenly from the normal as the fetus outgrows the capacity of the placenta. Readings taken every other day are often required at this stage to pick up any significant alterations.

In all these conditions, the higher risk to the fetus has been suspected from history or physical signs. Perhaps even more fundamental would be the detection of unsuspected fetal effect by routine 24-hr oestriol estimations performed at 30-36 weeks' gestation in all pregnant women. Beischer and Brown (1972) have shown that if the urinary oestrogen excretion levels are subnormal at these times, the perinatal mortality rate and incidence of intrauterine growth retardation are very high.

Such a screening test might be useful applied routinely in the antenatal clinic. Urinary oestrogen assays have been of less use in management of the diabetic pregnancy or the Rhesus affected mother. In the former the values may be lower than usual throughout and in the latter they may be kept artificially high by the hypertrophic placenta.

TABle 1. Percentage of two populations of antenatal women who showed certain high risk factors; the division into normal $(n=628)$ and subnormal $(n=70)$ is based on the oestrogen excretion measured routinely at the antenatal clinic at 30 and 36 weeks. After Beischer \& Brown (1972)

\begin{tabular}{lcc}
\hline & Normal & Subnormal \\
\hline $\begin{array}{l}\text { Stillbirths } \\
\begin{array}{l}\text { Neonatal } \\
\text { deaths }\end{array}\end{array}$ & 0.3 & $15 \cdot 7$ \\
$\begin{array}{l}\text { Major } \\
\text { malformations }\end{array}$ & $1 \cdot 3$ & 8.6 \\
$\begin{array}{l}\text { Small-for-dates } \\
\text { below tenth cen- } \\
\text { tile }\end{array}$ & 0.8 & 8.6 \\
\hline
\end{tabular}

All the problems associated with the collection of 24-hr urine samples have stimulated the use of single plasma assays. Mathur et al. (1973) found highly significant correlations between total plasma oestriol (determined fluorimetrically) and urinary oestriol levels in both uncomplicated and complicated pregnancies. Using a radioimmunoassay technique for the determination of total plasma oestriol levels, Masson $(1973 a, b, c)$ concluded that serial total plasma oestriol levels gave a better indication of feto-placental function than urinary oestriol determinations. Plasma oestriol levels were abnormal in patients with pre-eclampsia and in some patients, the plasma oestriol curve deviated from normal before clinical signs of pre-eclampsia became apparent. 
To compare the usefulness of the assay of plasma unconjugated oestrogens with urinary excretion, a series of fifty high-risk patients with single pregnancies were assessed at Queen Charlotte's Maternity Hospital. These women were all in-patients on whom bi-weekly 24-hr total urinary oestrogen excretion was being checked and on each day that a urine collection was completed, a $5 \mathrm{ml}$ sample of venous blood was withdrawn for the determination of unconjugated plasma oestrone, oestradiol and oestriol. The method used was a radioimmunoassay based on those reported by Emment, Collins and Sommerville (1972) and Youssefnejadian and Sommerville (1973).

The patients were divided into two groups.

Group 1: patients whose pregnancy was considered to have a normal outcome.

Group 2: patients delivered of infants with a birthweight less than the fifth centile.

The assay results are shown in Fig. 2. The ideal assay would be one with a normal range which is narrow and does not overlap with levels in pathological conditions. As can be seen in the figure none of the assays reported approach this ideal. The results obtained on the patients in each group were compared on a 'weeks before delivery' basis to see if
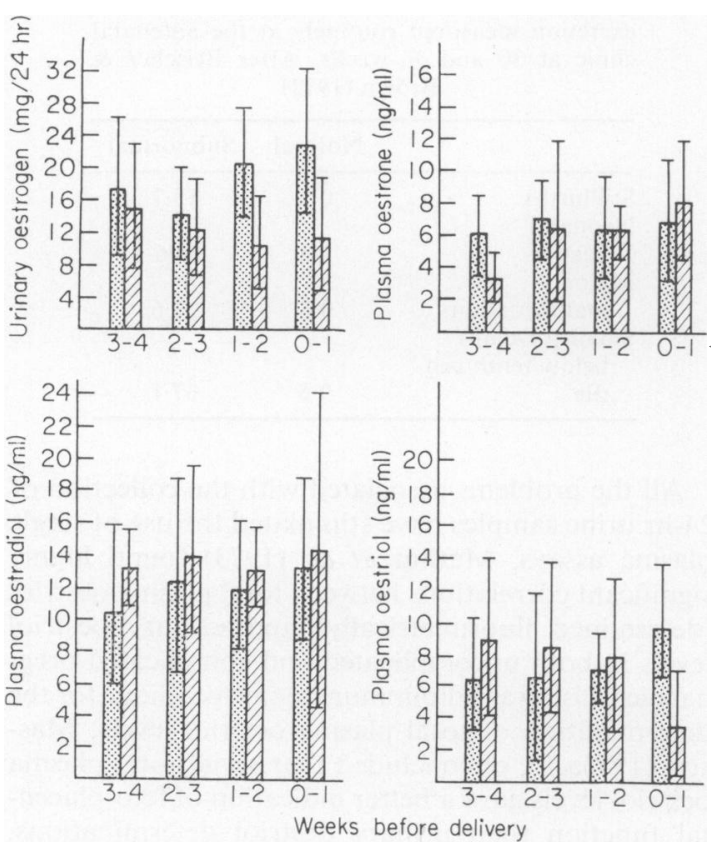

Fig. 2. The levels (mean \pm 1 s.d.) of urinary oestrogen and plasma oestrone, oestradiol and oestriol in the last 4 weeks of pregnancy in two groups of patients. mal; $\mathbb{Z}$, low birth-weight. See text for explanation. there were any statistically significant differences at the $5 \%$ level (Table 2).

For the management of pregnancy none of these assays would seem to be of value on a single sample basis. Serial blood assays, as routinely performed for urinary oestrogens, might be better indicators of fetal well-being, particularly predicting small-fordates infants, but there were insufficient data from this study to establish this.

TABLE 2. Statistically significant differences at the $5 \%$ level (indicated by + ) between normal and low birthweight groups in the last 4 weeks of pregnancy, using a $t$-test modified for small samples (Bailey, 1959)

\begin{tabular}{lllll}
\hline & \multicolumn{4}{c}{ Days before delivery } \\
\cline { 2 - 5 } $\begin{array}{l}\text { Steroid } \\
\text { assays }\end{array}$ & $28-22$ & $21-15$ & $14-8$ & $7-0$ \\
\hline $\begin{array}{l}\text { Urinary } \\
\text { oestrogens }\end{array}$ & & & + & + \\
$\begin{array}{l}\text { Plasma } \\
\text { oestrone }\end{array}$ & + & & & \\
$\begin{array}{l}\text { Plasma } \\
\text { oestradiol }\end{array}$ & + & & & \\
Plasma \\
oestriol
\end{tabular}

The ideal steroid assay of fetal well-being remains to be found. The assay of unconjugated oestrogens in plasma would not seem to be of great value. Total plasma oestriol has been claimed by many to be of value equal to the urinary assay (Klopper, 1975; Masson, 1973 a, b, c). Other steroids which have attracted attention are oestetrol, a unique metabolite of the fetal liver (Tulchinsky et al., 1975), oestriol-3sulphate (Klopper, 1976) which is not involved in the enterohepatic circulation nor resorbed from the gut and 16 $\beta$-hydroxyprogesterone (Klopper, 1975).

At present, the best use of any steroid assay for monitoring fetal well-being is to correlate it with other measures of fetal activity (such as ultrasound estimates of fetal growth) and use the composite picture as a guide to fetal health. Considered alongside the clinical data, the obstetrician can use the combined information to decide if the risks of staying inside the uterus exceed those of getting the fetus out. He is thus better equipped to determine the best time for, and route of, delivery and is made aware if extra care in labour is needed.

\section{References}

BAILEY, N.T.J. (1959) The use of $t$-tests for small samples. In: Statistical Methods in Biology (Ed. by W. S. Bullough), p. 43. The English Universities Press Ltd, London.

Beischer, N.A. \& Brown, J.B. (1972) Current status of estrogen assays in obstetrics and gynecology. Obstetrical and Gynecological Survey, 27, 303.

Brown, J.B., Bulbrook, R.D. \& Greenwood, F.C. (1957) An additional purification step for a method for estimating oestriol, oestrone and oestradiol-17 $\beta$ in human urine. Journal of Endocrinology, 16, 49. 
Chamberlain, G. (1975) Lecture Notes in Obstetrics. Blackwell, Oxford.

Diczfalusy, E. (1969) Steroid metabolism in the fetoplacental unit. In: The Fetoplacental Unit (Ed. by A. Pecile \& C. Finzi), p. 65, Exerpta Medica Foundation, Amsterdam.

Diczfalusy, E. \& Troen, P. (1961) Endocrine functions of the human placenta. Vitamins and Hormones, 19, 229.

Emment, Y., Collins, W.P. \& Sommerville, I.F. (1972) Radioimmunoassay of oestrone and oestradiol in human plasma. Acta endocrinologica. Copenhagen, 69, 567.

KLOPPER, A. (1969) The assessment of placental function in clinical practice. In: Fetus and Placenta (Ed. by A. Klopper \& E. Diczfalusy), p. 471. Blackwell Scientiflc Publications, Oxford.

KLOPPER, A. (1976) Steroids in late pregnancy. In: Research on Steroids (Proc. 7th Congr. Internat. Study Grp for Steroid Hormones. Rome, Dec. 1975), Vol. 7 (not yet published).

lamb, E., Mancuso, S., Dell'Acqua, S., Wiqvist, N. \& Diczfalusy, E. (1967) Studies on the metabolism of $C_{19^{-}}$ steroids in the human foeto-placental unit: 1. Neutral metabolites formed from dehydroepiandrosterone and dehydroepiandrosterone sulphate by the placenta at midpregnancy. Acta endocrinologica. Copenhagen, 55, 263.

Levitz, M., Emerman, S. \& Dancis, J. (1962) Sterol synthesis in perfused human placenta. Exerpta Medica (Amsterdam), International Congress Series, 51, 226.

MacNaughton, M.C. (1969) The foeto-placental unit. In: Modern Trends in Obstetrics (Ed. by R. J. Kellar), Vol. 4, p. 110. Butterworths, London.

Masson, G.M. (1973a) Plasma oestriol concentration during normal pregnancy. Journal of Obstetrics and Gynaecology of the British Commonwealth, 80, 201.

Masson, G.M. (1973b) Plasma oestriol in pre-eclampsia. Journal of Obstetrics and Gynaecology of the British Commonwealth, 80, 206.
Masson, G.M. (1973c) Plasma oestriol in retarded intrauterine foetal growth. Journal of Obstetrics and Gynaecology of the British Commonwealth, 80, 423.

Mathur, R.S., Chestnut, S.K., Leaming, A.B. \& WilliamSON, H.O. (1973) Application of plasma estriol estimation in the management of high-risk pregnancies. American Journal of Obstetrics and Gynecology) 117, 210.

Pion, R., Conrad, S.H. \& Wolf, B.J. (1966) Pregnenolone sulphate: An efficient precursor for the placental production of progesterone. Journal of Clinical Endocrinology, 26, 225.

Pion, R., Jaffe, E., Eriksson, G., WiQvist, N. \& DiczFalusy, E. (1965) Studies on the metabolism of $\mathrm{C}_{21}$ steroids in the human foeto-placental unit: 1 . Formation of $\alpha, \beta$ unsaturated 3 -ketones in the mid-term placentas perfused in situ with pregnenolone and 17 $\alpha$-hydroxypregnenolone. Acta endocrinologica. Copenhagen, 48, 234.

Russell, C.S., Paine, C.G., Coyle, M.G. \& Dewhurst, C.J. (1957) Pregnanediol excretion in normal and abnormal pregnancy. Journal of Obstetrics and Gynaecology of the British Commonwealth, 64, 649.

Solomon, S. (1967) In: Proceedings of the Second Conference on Fetal Homeostasis, Princeton, N.J. (Ed. by R. Wynn), p. 140.

Solomon, S., Bird, C.E., Ling, W., Iwamiya, M. \& Young, P.C.M. (1967) Formation and metabolism of steroids in the fetus and placenta. Recent Progress in Hormone Research, 23, 297.

Tulchinsky, D., Frigoletto, F.D., JR, Ryan, K.J. \& FishMAN, J. (1975) Plasma estetrol as an index of fetal wellbeing. Journal of Clinical Endocrinology, 40, 560.

Youssefnejadian, E. \& Sommerville, I.F. (1973) Radioimmunoassay of plasma oestriol. Journal of Steroid Biochemistry, 4, 659. 